Article

\title{
Prevalence and Factors Related to Natural Resistance-Associated Substitutions to Direct-Acting Antivirals in Patients with Genotype 1 Hepatitis C Virus Infection
}

\author{
Isabella Esposito ${ }^{1}$, Sebastián Marciano ${ }^{2,3}$, Leila Haddad ${ }^{2}$, Omar Galdame ${ }^{2}$, Alejandra Franco ${ }^{1}$, \\ Adrián Gadano ${ }^{1,2,3}$, Diego Flichman ${ }^{4,5}$ and Julieta Trinks ${ }^{1, *(D)}$ \\ 1 Instituto de Medicina Traslacional e Ingeniería Biomédica (IMTIB), CONICET, Instituto Universitario del \\ Hospital Italiano (IUHI), Hospital Italiano (HIBA), C1199ACL Buenos Aires, Argentina; \\ isabellesposito@gmail.com (I.E.); alejandra.franco@hospitalitaliano.org.ar (A.F.); \\ adrian.gadano@hospitalitaliano.org.ar (A.G.) \\ 2 Sección de Hepatología, Servicio de Clínica Médica, Hospital Italiano de Buenos Aires, \\ C1199ABB Buenos Aires, Argentina; sebastian.marciano@hospitalitaliano.org.ar (S.M.); \\ leila.haddad@hospitalitaliano.org.ar (L.H.); omar.galdame@hospitalitaliano.org.ar (O.G.) \\ 3 Departamento de Investigación, Hospital Italiano de Buenos Aires, C1199ABB Buenos Aires, Argentina \\ 4 Cátedra de Virología, Facultad de Farmacia y Bioquímica, Universidad de Buenos Aires, \\ C1113AAD Buenos Aires, Argentina; dflichman@ffyb.uba.ar \\ 5 Consejo Nacional de Investigaciones Científicas y Técnicas (CONICET), C1425FQB Buenos Aires, Argentina \\ * Correspondence: julieta.trinks@hospitalitaliano.org.ar; Tel.: +54-11-4959-0200 (ext. 4951)
}

Received: 26 October 2018; Accepted: 19 December 2018; Published: 21 December 2018

check for updates

\begin{abstract}
This study aimed to assess the prevalence of natural resistance-associated substitutions (RASs) to NS3, NS5A and NS5B inhibitors in 86 genotype 1 Hepatitis C Virus (HCV)-infected patients from Buenos Aires, Argentina, and to determine their effect on therapy outcome. Additionally, virological, clinical and host genetic factors were explored as predictors of the presence of baseline RASs. NS3 RASs (39.2\%) were more prevalent than NS5A RASs (25\%) and NS5B RASs (8.9\%). In the three regions, the frequencies of RASs were significantly higher in HCV-1b than in HCV-1a. The prevalence of $\mathrm{Y93H}$, L159F and Q80K were 1.3\%, 6.3\% and 2.5\%, respectively. IFNL3 CC genotype was identified as an independent predictor of the presence of baseline RASs in NS5A and NS3 genes ( $p=0.0005$ and $p=0.01$, respectively). Sustained virologic response was achieved by $93.3 \%$ of the patients after receiving direct-acting antivirals (DAAs), although $48.7 \%$ of them showed baseline RASs related to the DAA-regimen. Notably, the prevalence of clinically relevant RASs in the three genes was lower than that observed around the world. The baseline presence of RASs in both subtypes did not appear to affect therapy outcome. These results support the need to evaluate resistance patterns in each particular country since RASs' prevalence significantly vary worldwide.
\end{abstract}

Keywords: hepatitis C virus; resistance-associated substitutions; direct-acting antivirals; quasispecies

\section{Introduction}

Hepatitis C Virus (HCV) infection affects more than 70 million people worldwide [1,2]. Argentina is considered a low-endemicity country, with a prevalence that is estimated to be around 1\% [3]; although higher rates have been described in different small rural communities [4].

The treatment of chronic HCV infection has considerably improved in recent years with the widespread development of "direct-acting antiviral" (DAA) drugs. These drugs, which target specific viral proteins of the HCV lifecycle, can be combined in highly effective, well-tolerated, interferon-free 
treatment regimens [5,6]. Currently available HCV DAAs are classified into four categories on the basis of their molecular target in the viral replication cycle and mechanism of action: NS3/4A protease inhibitors, NS5A inhibitors, nucleotide analogue inhibitors of NS5B RNA-dependent RNA polymerase (RdRp), and non-nucleoside inhibitors of RdRp. Each drug family has a specific resistance profile that influences the barrier to resistance and may vary among HCV genotypes and subtypes $[7,8]$. In this regard, different combinations of simeprevir (SMV), sofosbuvir (SOF), paritaprevir (PTV), daclatasvir (DCV), ledipasvir (LDV), ombitasvir (OMV), dasabuvir (DSV), velpatasvir (VLP), grazoprevir (GZR) and elbasvir (ELB), have already been approved by the regulatory system and are currently available in Argentina [9].

Despite the high rates of sustained virologic response (SVR) (over 90\%), the effectiveness of new DAAs may be compromised by the emergence of resistance-associated variants (RAVs) [6,10-12]. The development of drug resistance is indeed an intrinsic, and to some extent unavoidable, characteristic of antiviral therapies. The combination of the high replication rate of $\mathrm{HCV}$, along with the low fidelity and the lack of proof-reading mechanisms of its RNA dependent RNA polymerase, results in a highly variable viral population known as "quasispecies" within each infected individual. This large heterogeneity in viral gene sequences and natural dynamic variability promotes the rapid emergence of RAVs [13].

An RAV is defined by the presence of one or more resistance-associated substitutions (RASs), amino acid substitutions able to adversely impact the activity of DAAs in vitro and/or in vivo in treated patients [14]. Resistance-associated substitutions (RASs) may arise during therapy or may pre-exist at baseline, increasing the likelihood of treatment failure [6,10-12,15]. In particular, natural changes in HCV NS3, NS5A and NS5B genes associated with reduced drug sensitivity have been observed in DAA treatment-naïve patients [6]. Therefore, even prior to treatment, RAVs may exist as minor variants at baseline, which would rapidly become dominant under the selective pressure exerted by the drugs, subsequently leading to a virological breakthrough during treatment or a relapse after treatment cessation $[6,14]$.

The prevalence of these naturally occurring RASs has been examined using standard population (Sanger) sequencing. Unfortunately, this conventional method is not sensitive enough in detecting clinically relevant variants present in less than $20 \%$ of the viral population [16]. In this regard, next-generation sequencing (NGS) technologies have demonstrated to be a useful tool to detect minor variants at baseline [17].

The utility of RAS testing depends upon both patient characteristics and DAA regimen. At present, RASs detection at baseline is particularly important in patients infected with HCV genotypes 1a and 3 [12]. Even though treatment-associated RASs are clinically more important than natural RASs, the latter might negatively impact treatment with some regimens like ELB/GZR and SMV/SOF in patients infected with genotype 1a [12]. Nevertheless, until newer DAAs become extensively available in all countries, and the issue of resistance will not be overcome, the HCV genotypic resistance testing is, and will be, an essential diagnostic tool for tailoring personalized treatments, particularly after a DAA-failure [12].

Emerging data have suggested that complex interactions between factors related to the infecting virus (genotypes, viral load, RASs) and to the host (age, gender, degree of liver fibrosis, alcohol consumption, etc.) would predict HCV treatment success and/or improve safety $[8,18]$. In fact, significant associations have been reported between natural RASs and host genetic determinants in the interferon lambda 3 (IFNL3) and 4 (IFNL4) genes, identified as predictors of Pegylated Interferon and Ribavirin (PegIFN/RBV) response in chronic HCV [19-21].

Given that natural RASs that might confer DAAs resistance exhibit geographical differences in their frequencies [22], the interpretation of the resistance profile is very complex, and the need of resistance testing should be defined in each country. In this regard, the prevalence of natural RASs has not been extensively studied in Argentina. Therefore, the aim of this study was to estimate the prevalence of RASs within NS3, NS5A and NS5B genomic regions in DAA-naïve patients chronically 
infected with HCV genotype 1, by automated Sanger sequencing and Ion Torrent NGS, and to determine their effect on therapy outcome. Additionally, virological, clinical and host genetic factors were explored as predictors of the presence of baseline RASs.

\section{Materials and Methods}

\subsection{Study Population}

This study was approved a priori by the Ethics Committee on Research from the Hospital Italiano of Buenos Aires and conducted in accordance with good clinical practice guidelines and the principles of the Declaration of Helsinki.

From 2012 to 2014, consecutive DAA-naïve patients with genotype 1 chronic hepatitis C were invited to participate in the study, which took place at the Hepatology Unit of the Hospital Italiano of Buenos Aires. Serum and whole blood samples were collected from each patient, after obtaining written informed consent.

Clinical data, such as gender, age and previous failure to PegIFN/RBV treatment, were recorded. To evaluate the impact of baseline RASs on treatment outcome, SVR rates were documented in those patients who underwent DAA prescription after recruitment and sample collection. Fibrosis grade was staged either by biopsy or Transient Elastography by Fibroscan ${ }^{\circledR}($ Echosens, Paris, France).

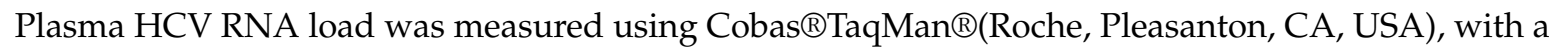
detection limit of $15 \mathrm{IU} / \mathrm{mL}$. HIV co-infection was diagnosed by ELISA (Dade Behring; Enzygnost anti HIV-1/2 plus, Marburg GmbH, Germany) and confirmed by Western-blot (New Lab Blot-1, Bio-Rad, Marnes-la-Coquette, France).

\subsection{RT-PCR and Automated Sanger Sequencing}

NS3, NS5A and NS5B genomic regions were partially amplified by previously described RT-Nested PCR protocols specific for subtype $1 \mathrm{a}$ and $1 \mathrm{~b}$ [23-25], covering positions involved in drug resistance. PCR products were bi-directionally sequenced using the Big-Dye Termination chemistry system (Applied Biosystems, Foster City, CA, USA).

$\mathrm{HCV}$ genotype and subtype were confirmed in each genomic region by phylogenetic analysis. BioEdit (v.7.2.5) software [26] was used for sequence alignment. Phylogenetic trees were constructed using the maximum-likelihood method in MEGA (v.6.0) [27], and visualized in TreeView v.1.6.6 [28]. Nucleotide sequences were deposited in GenBank under accession numbers MH733012-MH733240 and MK215006-MK215017.

\subsection{NGS Sequencing}

Amplicons were fragmented into 200 base pair (bp) pieces using Bioruptor®Sonication System (Diagenode, Denville, NJ, USA). Fragments were nick repaired, adaptor ligated, and barcoded using the Ion Neb Next Library kit (Life Technologies, Foster, CA, USA). Then, fragments were purified by Agencourt ${ }^{\circledR} A M P$ ure ${ }^{\circledR X P}$ magnetic beads (Beckman Coulter, Brea, CA, USA), the fragmentation pattern was analyzed by semi-fluidic electrophoresis (Agilent ${ }^{\circledR B i o a n a l y z e r}{ }^{\circledR}$, Santa Clara, CA, USA) and libraries were diluted to obtain equimolar amounts. Emulsion PCR was carried out using the Ion OneTouchTM 2.0 system (Life Technologies, Carlsbad, CA, USA) and the Ion PGMTM Template Hi-Q ${ }^{\mathrm{TM}}$ OT2 200 kit (Thermo Fisher Scientific, Waltham, MA, USA), followed by an enrichment step. Sequencing was performed on an Ion Torrent Personal Genome Machine (PGM) sequencer (Thermo Fisher Scientific, Waltham, MA, USA) using the Ion PGM ${ }^{\mathrm{TM}} \mathrm{Hi}^{-\mathrm{Q}^{\mathrm{TM}}}$ Sequencing Kit and the Ion 316 chip (Thermo Fisher Scientific, Waltham, MA, USA).

\subsection{RASs Analysis}

RASs were defined as a change in the RNA sequence associated to in vivo (with treatment failure) and/or in vitro phenotypic assays (to confer more than 2.5-fold change in drug susceptibility in 
comparison to the wild-type reference strain). RASs summarized by a recent systematic review [15] were selected for the analysis in this study. Overall, nine NS5A $(24,28,30,31,32,38,58,92$ and 93), three NS5B (159, 237 and 282) and 14 NS3 positions (36, 41, 43, 54, 55, 56, 80, 122, 155, 156, 158, 168, 170 and 175) were analyzed in this study. Nucleotide sequences obtained from automated Sanger sequencing were aligned and compared with reference sequences for subtype 1a (AF009606) and 1b (AJ238799), using BioEdit (v.7.2.5) software [26].

All NGS reads were trimmed and aligned with the previously mentioned reference sequences using the Smith-Waterman algorithm, included in the Torrent Suite ${ }^{\mathrm{TM}}$ software (Thermo Fisher Scientific, Waltham, MA, USA). The plugins Variant Caller and Coverage Analyzer, both available in this software, were used for analysis of sequence variants and coverage, respectively. Low stringency parameters were used to identify variants, as previously reported [17]. Sequence data were visually confirmed with the Integrative Genomics Viewer and any sequence, alignment, or variant call error artifacts were discarded.

\subsection{HCV Quasispecies Analysis}

Sequencing errors induced by PCR and ultra-deep sequencing would complicate the analysis of viral populations and result in inflated estimates of quasispecies heterogeneity. To avoid such misinterpretation, all necessary precautions in sample preparation, RNA extraction, and amplification were taken into account [29], and PCR bias was avoided as previously reported [30]. In addition, ShoRAH (v.0.8) software, which applied a probabilistic Bayesian approach to minimize the effects of errors, was used [31].

The quasispecies complexity of NS3, NS5A and NS5B was determined by calculating: Nucleotide mutation frequency (Pn) and normalized Shannon entropy (Sn). Pn was calculated as the total number of polymorphic sites divided by the total number of nucleotides sequenced; considering that the variability of the quasispecies increased as Pn increased. The measure of the Shannon entropy, defined in terms of the probabilities of different sequences that can appear at a given time point was calculated using the formula $S=-\Sigma i$ (pi ln pi), where pi is the frequency of each variant in the viral quasispecies. The normalized entropy, $S n$, was calculated as $S n=S / \ln N$, where $N$ is the total number of sequences analyzed in each sample. Sn theoretically varies from 0 (no diversity) to 1 (maximum diversity) [32].

\subsection{SNPs Genotyping}

SNPs rs12979860 (IFNL3) and rs368234815 (IFNL4) were genotyped by PCR [21] followed by bi-directional sequencing using Big-Dye Termination chemistry system. BioEdit (v.7.2.5) software [26] was used to discriminate between homozygotes and heterozygotes.

\subsection{Evaluated Variables and Statistical Analyses}

For descriptive statistics, mean and standard deviation (SD) or absolute number and percentages were used. The statistical analysis of data was performed by means of contingency tables using Fisher exact probability test for categorical variables and Mann-Whitney $U$ test for continuous variables. Univariate and multivariate logistic analyses were performed to identify variables that were independently associated with the presence of RASs in each genomic region. All significant parameters in the univariate analysis were included in the multivariate analysis. The virological variables that were explored to be associated with the presence of RASs were HCV subtypes, viral load and quasispecies complexity. Age, gender, METAVIR score and previous failure to PegIFN/RBV treatment were the clinical variables analyzed to be associated with RASs. Host SNPs in IFNL3/IFNL4 genes were also explored. Statistical analyses were performed with the Statistical Package for the Social Sciences software (v.18.0) (SPSS, Chicago, IL, USA) and significant differences were considered only for $p<0.05$. 


\section{Results}

\subsection{Patients' Characteristics}

A total of 86 consecutive DAA-naïve patients chronically infected with HCV genotype 1 (33 subtype 1a and 53 subtype 1b) were included in the study. The clinical, virological and host genetic characteristics of the patients are shown in Table 1.

Table 1. Main characteristics of the Hepatitis C Virus (HCV) genotype 1 patients recruited in this study.

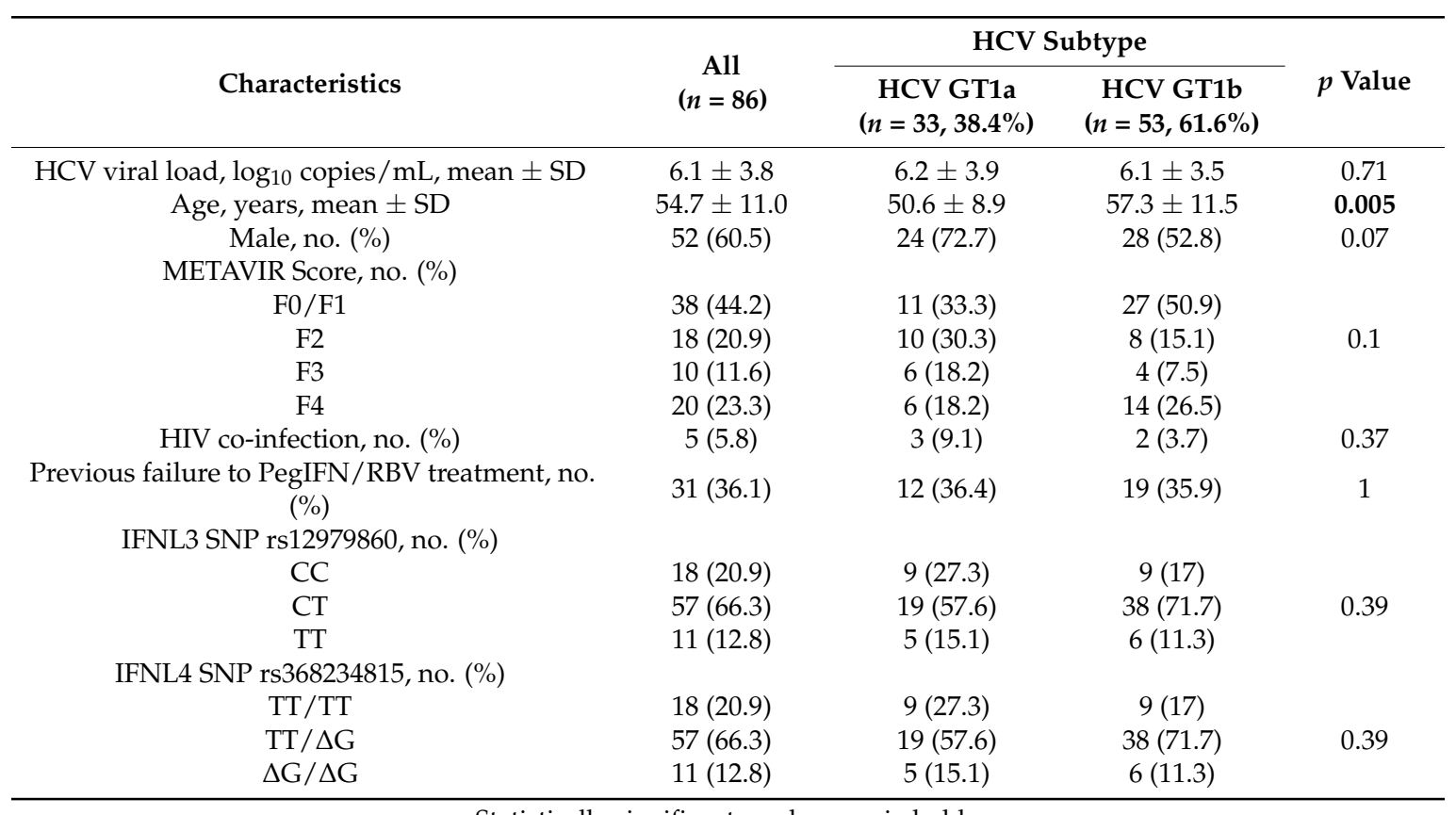

Statistically significant $p$ values are in bold.

\subsection{Prevalence of RASs in NS5A Protein}

The NS5A region was successfully amplified in 84 (97.7\%) samples: $51(60.7 \%)$ belonged to HCV subtype $1 \mathrm{~b}$ and 33 (39.3\%) to subtype 1a. The latter sequences clustered into clade 1 ( 25 sequences; $75.8 \%$ ) and clade 2 (eight sequences; 24.2\%) (Supplementary Figure S1). No difference was observed in the presence of RASs between both clades: 8/25 (32\%) in clade 1 and $4 / 8(50 \%)$ in clade $2(p=0.42)$.

A total of $14(16.7 \%)$ sequences exhibited RASs among the 84 analyzed patients, being the prevalence significantly higher in subtype $1 \mathrm{~b}(13 / 51 ; 25.5 \%)$ when compared to subtype $1 \mathrm{a}(1 / 33 ; 3 \%)$ $(p=0.007)$.

Among the 51 subtype $1 \mathrm{~b}$ sequences, RASs L28M (2\%), L31M (2\%), L31F (2\%), and R30Q (13.7\%) considered as primary resistance mutations to DCV, ELB, LDV and OMV, were identified. Substitutions detected at positions 58 - which confers resistance to VLP-and 92-associated with resistance to LDV and OMV—were P58R/T (4\%) and A92T (2\%), respectively (Table 2). 
Table 2. Frequency of resistance-associated substitutions (RASs) in the NS5A protein by automated Sanger sequencing data.

\begin{tabular}{|c|c|c|c|}
\hline Genotype & $\begin{array}{l}\text { Reference NS5A } \\
\text { Position }\end{array}$ & RASs & Frequency \\
\hline \multirow{9}{*}{$1 \mathrm{a}$} & K24 & $\mathrm{R}$ & - \\
\hline & M28 & $\mathrm{A} / \mathrm{G} / \mathrm{T} / \mathrm{S} / \mathrm{V}$ & M28V (1/33; 3\%) \\
\hline & Q30 & $\mathrm{D} / \mathrm{E} / \mathrm{G} / \mathrm{H} / \mathrm{K} / \mathrm{L} / \mathrm{N} / \mathrm{R} / \mathrm{Y}$ & - \\
\hline & L31 & $\mathrm{F} / \mathrm{I} / \mathrm{M} / \mathrm{V}$ & - \\
\hline & P32 & $\mathrm{L}$ & - \\
\hline & S38 & $\mathrm{F}$ & - \\
\hline & H58 & $\mathrm{D}$ & - \\
\hline & A92 & $\mathrm{K} / \mathrm{T}$ & - \\
\hline & Y93 & $\mathrm{C} / \mathrm{F} / \mathrm{H} / \mathrm{L} / \mathrm{N} / \mathrm{R} / \mathrm{S} / \mathrm{T} / \mathrm{W}$ & - \\
\hline \multirow{9}{*}{$1 b$} & Q24 & $\mathrm{K}$ & - \\
\hline & L28 & $\mathrm{M} / \mathrm{T}$ & L28M (1/51;2\%) \\
\hline & $\mathrm{R} 30$ & $\mathrm{G} / \mathrm{H} / \mathrm{Q} / \mathrm{S}$ & R30Q $(7 / 51 ; 13.7 \%)$ \\
\hline & L31 & $\mathrm{F} / \mathrm{I} / \mathrm{M} / \mathrm{V}$ & L31M $(1 / 51 ; 2 \%)$ \\
\hline & & & $\operatorname{L31F}(1 / 51 ; 2 \%)$ \\
\hline & P58 & $\mathrm{A} / \mathrm{D} / \mathrm{L} / \mathrm{R} / \mathrm{S} / \mathrm{T}$ & P58R (1/51; 2\%) \\
\hline & & & P58T (1/51; $2 \%)$ \\
\hline & A92 & $\mathrm{K} / \mathrm{T}$ & A92T (1/51; 2\%) \\
\hline & Y93 & $\mathrm{C} / \mathrm{H} / \mathrm{I} / \mathrm{N} / \mathrm{R} / \mathrm{S} / \mathrm{T}$ & - \\
\hline
\end{tabular}

Among the 33 subtype 1a strains, the primary resistance mutation $\mathrm{M} 28 \mathrm{~V}$, related to resistance to LDV and OMV, was observed in one (3\%) sample. (Table 2).

No combinations of multiple RAS were observed in subtype $1 \mathrm{a}$, whereas in subtype $1 \mathrm{~b}$, one patient $(2 \%)$ carried two mutations being the genetic profile R30Q+P58R.

\subsection{Prevalence of RASs in NS5B Polymerase}

The NS5B region was successfully amplified in 79 (91.9\%) samples: $49(62 \%)$ belonged to HCV subtype $1 \mathrm{~b}$ and 30 (38\%) to subtype 1a. The latter sequences split into clade 1 ( 22 sequences; $73.3 \%$ ) and clade 2 (eight sequences; 26.7\%) (Supplementary Figure S2). No difference was observed in the presence of RASs between both clades: $4 / 22(18.2 \%)$ in clade 1 and $3 / 8(37.5 \%)$ in clade $2(p=0.34)$.

Screening and analysis of NS5B residues 1 to 300 detected RASs at positions 159 and 282 in seven $(8.9 \%)$ of the 79 sequences, all of them ascribed to subtype $1 \mathrm{~b}$. Therefore, the prevalence of RASs was significantly higher in subtype $1 \mathrm{~b}(7 / 49 ; 14.3 \%)$ when compared to subtype $1 \mathrm{a}(0 \%)(p=0.04)$.

Among the 49 subtype $1 \mathrm{~b}$ sequences, five $(10.2 \%)$ harbored the L159F variant, associated with a lower response to SOF. Although the major mutation S282T, which confers high-level resistance to SOF, was not observed, RASs S282G (4.1\%) was detected (Table 3).

No combinations of multiple RASs were observed in subtype 1a- or 1b-infected patients.

Table 3. Frequency of RASs in the NS5B polymerase by automated Sanger sequencing data.

\begin{tabular}{cccc}
\hline Genotype & Reference NS5B Position & RASs & Frequency \\
\hline \multirow{2}{*}{$1 \mathrm{a}$} & $\mathrm{L} 159$ & $\mathrm{~F}$ & - \\
& $\mathrm{E} 237$ & $\mathrm{G}$ & - \\
& $\mathrm{S} 282$ & $\mathrm{R} / \mathrm{T}$ & - \\
\hline \multirow{2}{*}{$1 \mathrm{~b}$} & $\mathrm{~L} 159$ & $\mathrm{~F}$ & $\mathrm{~L} 159 \mathrm{~F}(5 / 49 ; 10.2 \%)$ \\
& $\mathrm{S} 282$ & $\mathrm{G} / \mathrm{T}$ & $\mathrm{S} 282 \mathrm{G}(2 / 49 ; 4.1 \%)$ \\
\hline
\end{tabular}

\subsection{Prevalence of RASs in NS3 Protease}

The NS3 gene was successfully amplified in 79 (91.9\%) samples: 50 were ascribed to HCV subtype $1 \mathrm{~b}(63.3 \%)$ and 29 to subtype $1 \mathrm{a}(36.7 \%)$. The latter sequences clustered into clade 1 (22 sequences; 
$75.9 \%$ ) and clade 2 (seven sequences; $24.1 \%$ ) (Supplementary Figure S3). No difference was observed in the presence of RASs between both clades: $5 / 22(22.7 \%)$ in clade 1 and $3 / 7(42.9 \%)$ in clade $2(p=0.36)$.

RASs were found in $22(27.8 \%)$ of the 79 sequences, and their overall prevalence was higher in subtype $1 \mathrm{~b}(18 / 50 ; 36 \%)$ than in subtype $1 \mathrm{a}(4 / 29 ; 13.8 \%)(p=0.04)$.

Among the 29 subtype 1a strains, the clinically relevant RASs Q80K, associated with resistance to SMV, GZR and PTV, was detected only in one (3.4\%) sample ascribed to subtype 1a clade 1. Substitution T54S, associated with resistance to ASV and SMV, was found in one (2\%) sequence; as well as RAS V36L, which confers resistance to SMV, GZR and PTV, and I170V associated with resistance to SMV (Table 4).

Table 4. Frequency of RASs in the NS3 protease by automated Sanger sequencing data.

\begin{tabular}{|c|c|c|c|}
\hline Genotype & $\begin{array}{c}\text { Reference NS3 } \\
\text { Position }\end{array}$ & RASs & Frequency \\
\hline \multirow{12}{*}{$1 \mathrm{a}$} & V36 & $\mathrm{A} / \mathrm{G} / \mathrm{M} / \mathrm{L}$ & V36L $(1 / 29 ; 3.4 \%)$ \\
\hline & Q41 & $\mathrm{R}$ & - \\
\hline & F43 & S & - \\
\hline & $\mathrm{T} 54$ & $\mathrm{~A} / \mathrm{S}$ & T54S $(1 / 29 ; 3.4 \%)$ \\
\hline & Y56 & $\mathrm{F} / \mathrm{H}$ & - \\
\hline & Q80 & $\mathrm{K} / \mathrm{R}$ & Q80K $(1 / 29 ; 3.4 \%)$ \\
\hline & S122 & $\mathrm{R}$ & - \\
\hline & R155 & $\mathrm{I} / \mathrm{G} / \mathrm{K} / \mathrm{N} / \mathrm{Q} / \mathrm{S} / \mathrm{T} / \mathrm{W}$ & - \\
\hline & A156 & $\mathrm{G} / \mathrm{L} / \mathrm{M} / \mathrm{S} / \mathrm{T} / \mathrm{V}$ & - \\
\hline & V158 & A & - \\
\hline & D168 & $\mathrm{A} / \mathrm{C} / \mathrm{E} / \mathrm{F} / \mathrm{G} / \mathrm{H} / \mathrm{I} / \mathrm{K} / \mathrm{L} / \mathrm{N} / \mathrm{R} / \mathrm{S} / \mathrm{T} / \mathrm{V} / \mathrm{Y}$ & - \\
\hline & $\mathrm{I} 170$ & $\mathrm{~T} / \mathrm{V}$ & I170V $(1 / 29 ; 3.4 \%)$ \\
\hline \multirow{15}{*}{$1 b$} & V36 & $\mathrm{A} / \mathrm{G} / \mathrm{M}$ & - \\
\hline & Q41 & $\mathrm{R}$ & - \\
\hline & F43 & $\mathrm{L} / \mathrm{S} / \mathrm{V}$ & - \\
\hline & T54 & $\mathrm{A} / \mathrm{S}$ & T54S $(1 / 50 ; 2 \%)$ \\
\hline & V55 & $\mathrm{A} / \mathrm{I}$ & - \\
\hline & Y56 & $\mathrm{F} / \mathrm{H}$ & Y56F (8/50; 16\%) \\
\hline & Q80 & $\mathrm{K} / \mathrm{L} / \mathrm{R}$ & Q80K (1/50;2\%) \\
\hline & & & Q80R (1/50; 2\%) \\
\hline & S122 & $\mathrm{D} / \mathrm{G} / \mathrm{R} / \mathrm{T}$ & S122G $(4 / 50 ; 8 \%)$ \\
\hline & & & $\mathrm{S} 122 \mathrm{~T}(2 / 50 ; 4 \%)$ \\
\hline & R155 & $\mathrm{K} / \mathrm{G} / \mathrm{L} / \mathrm{T} / \mathrm{Q} / \mathrm{W}$ & R155K $(1 / 50 ; 2 \%)$ \\
\hline & A156 & $\mathrm{G} / \mathrm{S} / \mathrm{T} / \mathrm{V}$ & - \\
\hline & D168 & $\mathrm{A} / \mathrm{C} / \mathrm{E} / \mathrm{F} / \mathrm{G} / \mathrm{H} / \mathrm{I} / \mathrm{K} / \mathrm{N} / \mathrm{Q} / \mathrm{T} / \mathrm{V} / \mathrm{Y}$ & - \\
\hline & V170 & $\mathrm{A} / \mathrm{T}$ & - \\
\hline & M175 & $\mathrm{L}$ & - \\
\hline
\end{tabular}

Among the 50 subtype $1 \mathrm{~b}$ strains, eight (16\%) sequences presented the mutation $\mathrm{Y} 56 \mathrm{~F}$ associated with resistance to GRZ, and six (12\%) exhibited the substitutions S122G/T associated with resistance to SMV. Variants at position 80 were detected in two (4\%) samples: The primary resistance RAS Q80K and the low-level resistance RAS to SMV Q80R. Substitution T54S which confers resistance to first-generation protease inhibitors, and R155 associated with resistance to first- and second-generation protease inhibitors, were found each in one (2\%) sequence (Table 4$)$.

No combinations of multiple RASs were observed in subtype 1a- or 1b-infected patients.

\subsection{Comparison of NGS and Direct Sequencing Results}

The NS5A, NS5B and NS3 genes were successfully sequenced by NGS in $76(90.5 \%), 72(91.1 \%)$ and $72(91.1 \%)$ of the samples characterized by automated Sanger sequencing, respectively. A mean of $12,259,169,10,968,036$ and 19,235,648 bp in the NS5A, NS5B and NS3 genes were mapped onto the reference sequences, and an overall average coverage depth of $889 x, 859 x$ and $987 x$ was achieved 
for each region, respectively. An average of $60,676,59,412$ and 90,748 reads of the NS5A, NS5B and NS3 regions were aligned and compared with reference sequences for each subtype, respectively. Deep sequencing yielded a median of $11,650,10,870$ and 12,340 sequences per sample in the NS5A, NS5B and NS3 genomic regions, respectively.

All RASs called by automated Sanger sequencing were confirmed by the NGS platform. Furthermore, deep sequencing (interpretative cut-off of $\geq 1 \%$ ) identified additional RASs with frequencies between $2 \%$ and $21 \%$ among the patient's viral quasispecies, in NS5A $(8 / 76 ; 10.5 \%)$ and NS3 $(9 / 72 ; 11.1 \%)$ but not in NS5B (Table 5).

Table 5. Prevalence of RASs in the NS5A and NS3 regions detected only by Next Generation Sequencing.

\begin{tabular}{|c|c|c|c|c|}
\hline $\begin{array}{l}\text { Genomic } \\
\text { Region }\end{array}$ & RASs & Patient No. & HCV Subtype & $\begin{array}{l}\text { Mutation Frequency } \\
\text { in Viral Quasispecies }\end{array}$ \\
\hline \multirow{8}{*}{ NS5A } & K24R & 87 & 1a & K24R (2\%) \\
\hline & Q24K & 80 & $1 b$ & $\mathrm{Q} 24 \mathrm{~K}(6.7 \%)$ \\
\hline & $\mathrm{M} 28 \mathrm{~A} / \mathrm{G} / \mathrm{T} / \mathrm{S} / \mathrm{V}$ & 4 & $1 \mathrm{a}$ & M28V (21\%) \\
\hline & R30G/H/Q/S & 10 & $1 b$ & $\mathrm{R} 30 \mathrm{H}(5.8 \%)$ \\
\hline & $\mathrm{L} 31 \mathrm{~F} / \mathrm{I} / \mathrm{M} / \mathrm{V}$ & 24 & $1 b$ & L31M (5.3\%) \\
\hline & $\mathrm{P} 58 \mathrm{~A} / \mathrm{D} / \mathrm{L} / \mathrm{R} / \mathrm{S} / \mathrm{T}$ & 97 & $1 b$ & P58S $(3.4 \%)$ \\
\hline & $\mathrm{A} 92 \mathrm{~K} / \mathrm{T}$ & 120 & $1 b$ & A92T $(4.2 \%)$ \\
\hline & Y93C/F/H/L/N/R/S/T/W & 4 & $1 \mathrm{a}$ & Y93H (3\%) \\
\hline \multirow{9}{*}{ NS3 } & $\mathrm{F} 43 \mathrm{~L} / \mathrm{S} / \mathrm{V}$ & 108 & $1 b$ & F43S (2\%) \\
\hline & $\mathrm{T} 54 \mathrm{~A} / \mathrm{S}$ & 62 & $1 b$ & T54S (3.5\%) \\
\hline & $\mathrm{Y} 56 \mathrm{~F} / \mathrm{H}$ & 106 & $1 b$ & Y56F (3.9\%) \\
\hline & & 90 & $1 b$ & Y56F (7.3\%) \\
\hline & & 74 & $1 b$ & Y56H $(4.1 \%)$ \\
\hline & Q80K/L/R & 40 & $1 b$ & Q80L (21\%) \\
\hline & $\mathrm{S} 122 \mathrm{D} / \mathrm{G} / \mathrm{R} / \mathrm{T}$ & 49 & $1 b$ & S122G (4.8\%) \\
\hline & & 88 & $1 b$ & S122G $(12 \%)$ \\
\hline & & 76 & $1 b$ & $\mathrm{~S} 122 \mathrm{~T}(3.9 \%)$ \\
\hline
\end{tabular}

\subsection{Assessment of HCV Quasispecies Diversity}

The viral population parameters of complexity of the NS5A, NS5B and NS3 genes sequenced by NGS, are summarized in Table 6.

Table 6. Mean genetic complexity in each viral genomic region by HCV subtype.

\begin{tabular}{|c|c|c|c|c|c|c|c|c|c|c|}
\hline \multirow[t]{2}{*}{$\begin{array}{l}\text { Genomic } \\
\text { Regions }\end{array}$} & \multicolumn{2}{|c|}{$\begin{array}{l}\text { HCV Subtype } \\
(n=)\end{array}$} & \multicolumn{2}{|c|}{$\begin{array}{c}\text { Mutations }{ }^{1 / N u c l e o t i d e s} \\
\text { Sequenced }\end{array}$} & \multicolumn{2}{|c|}{$\begin{array}{l}\text { Nucleotide } \\
\text { Mutation } \\
\text { Frequency }{ }^{2}\end{array}$} & \multirow[t]{2}{*}{$p$ Value } & \multicolumn{2}{|c|}{$\begin{array}{c}\text { Normalized } \\
\text { Shannon Entropy }\end{array}$} & \multirow[t]{2}{*}{$p$ Value } \\
\hline & $1 \mathrm{a}$ & $1 b$ & $1 \mathrm{a}$ & $1 b$ & $1 \mathrm{a}$ & $1 b$ & & $1 \mathrm{a}$ & $1 b$ & \\
\hline NS5A & 32 & 44 & $50 / 711$ & $75 / 715$ & 0.07 & 0.1 & 0.002 & 0.011 & 0.017 & 0.11 \\
\hline NS5B & 30 & 42 & $73 / 916$ & $78 / 945$ & 0.08 & 0.08 & 0.86 & 0.014 & 0.017 & 0.85 \\
\hline NS3 & 29 & 43 & $74 / 1007$ & $132 / 1300$ & 0.07 & 0.1 & 0.002 & 0.015 & 0.017 & 0.19 \\
\hline
\end{tabular}

${ }^{1}$ Mutations are those that vary when compared to the corresponding reference sequences; ${ }^{2}$ the nucleotide mutation frequency is the total number of mutations divided by the total number of nucleotides sequenced; ${ }^{3}$ the normalized Shannon entropy is calculated as $\mathrm{Sn}=-\left[\sum \mathrm{i}(\mathrm{pi} \ln \mathrm{pi})\right] / \ln \mathrm{N}$, in which pi is the proportion of each sequence of the mutant spectrum and $\mathrm{N}$ is the total number of sequences compared. Statistically significant $p$ values are in bold.

No significant associations were observed when these parameters were compared among the three analyzed HCV genomic regions. However, the nucleotide mutation frequencies for subtype 1a in NS3 and NS5A regions were significantly lower than those for subtype $1 \mathrm{~b}(p=0.002)$. Nucleotide mutation frequencies in the NS5B region as well as entropy values for all analyzed genomic regions were similar between subtype $1 \mathrm{a}$ and $1 \mathrm{~b}$ (Table 6 ). 
Table 7. Univariate and multivariate logistic regression analyses to identify independent factors associated with the presence of RASs in the NS5A gene (A), the NS5B region (B) and the NS3 gene $(\mathbf{C})$

A

\begin{tabular}{|c|c|c|c|c|c|}
\hline \multirow{2}{*}{ Patients Characteristics } & \multirow{2}{*}{$\begin{array}{l}\text { RASs } \\
(n=14)\end{array}$} & \multirow{2}{*}{$\begin{array}{c}\text { No RASs } \\
(n=70)\end{array}$} & \multirow{2}{*}{$\begin{array}{c}\text { Univariate Analysis } \\
p \text { Value }\end{array}$} & \multicolumn{2}{|c|}{ Multivariate Analysis } \\
\hline & & & & $p$ Value & OR $(95 \% \mathrm{CI})$ \\
\hline Male gender, no. (\%) & $9(64.3)$ & $41(58.6)$ & 0.77 & & \\
\hline Age (years), mean $\pm \mathrm{SD}$ & $53.4 \pm 5.1$ & $56.5 \pm 4.9$ & 0.77 & & \\
\hline $\mathrm{HCV}$ viral load $\left(\log _{10}\right)$, mean $\pm \mathrm{SD}$ & $6.2 \pm 3.2$ & $6.1 \pm 3.3$ & 0.47 & & \\
\hline HCV subtype $1 b$, no. $(\%)$ & $13(92.9)$ & $38(54.3)$ & 0.007 & 0.03 & $16.2(1.3-20.6)$ \\
\hline METAVIR Score F4, no. (\%) & $6(42.9)$ & $13(18.6)$ & 0.07 & & \\
\hline HIV co-infection, no. $(\%)$ & $2(14.3)$ & $3(4.3)$ & 0.19 & & \\
\hline Previous failure to PegIFN/RBV treatment, no. (\%) & $8(57.1)$ & $23(32.9)$ & 0.13 & & \\
\hline IFNL3 SNP (rs12979860) CC genotype a ${ }^{a}$ no. $(\%)$ & $10(71.4)$ & $8(11.4)$ & 0.0001 & 0.0005 & $16.8(3.4-8.2)$ \\
\hline Normalized Shannon Entropy $b$, mean \pm SD $(\times 1000)$ & $17 \pm 8.7$ & $10.3 \pm 3.6$ & 0.02 & 0.01 & $2.16(1.3-4.6)$ \\
\hline Nucleotide Mutation Frequency ${ }^{b}$, mean \pm SD $(\times 1000)$ & $9.8 \pm 4.5$ & $6.3 \pm 2.1$ & 0.004 & 0.009 & $4.7(1.4-15.2)$ \\
\hline
\end{tabular}

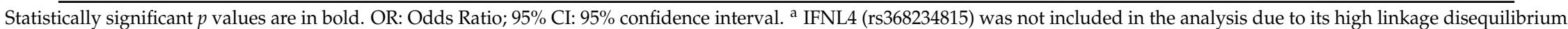
with IFNL3 (rs12979860) SNP in the analyzed population (Table 1). ${ }^{\mathrm{b}}$ Calculated on 76 samples.

B

\begin{tabular}{|c|c|c|c|c|c|}
\hline \multirow{2}{*}{ Patients Characteristics } & \multirow{2}{*}{$\begin{array}{l}\text { RASs } \\
(n=7)\end{array}$} & \multirow{2}{*}{$\begin{array}{l}\text { No RASs } \\
(n=72)\end{array}$} & \multirow{2}{*}{$\begin{array}{c}\text { Univariate Analysis } \\
p \text { Value }\end{array}$} & \multicolumn{2}{|c|}{ Multivariate Analysis } \\
\hline & & & & $p$ Value & OR $(95 \% \mathrm{CI})$ \\
\hline Male gender, no. (\%) & $5(71.4)$ & $43(59.7)$ & 0.7 & & \\
\hline Age (years), mean $\pm S D$ & $53.5 \pm 5.4$ & $50.3 \pm 5.6$ & 0.52 & & \\
\hline HCV viral load $\left(\log _{10}\right)$, mean \pm SD & $6.1 \pm 2.2$ & $5.9 \pm 2.6$ & 0.88 & & \\
\hline HCV subtype $1 b$, no. $(\%)$ & $7(100)$ & $42(58.3)$ & 0.04 & 0.99 & $1.7(0.40-1.41)$ \\
\hline METAVIR Score F4, no. (\%) & $3(42.9)$ & $17(23.6)$ & 0.36 & & \\
\hline HIV co-infection, no. $(\%)$ & $1(14.3)$ & $4(5.55)$ & 0.38 & & \\
\hline Previous failure to PegIFN/RBV treatment, no. (\%) & $5(71.4)$ & $29(40.3)$ & 0.13 & & \\
\hline IFNL3 SNP (rs12979860) CC genotype ${ }^{a}$, no. $(\%)$ & $2(28.6)$ & $12(16.7)$ & 0.6 & & \\
\hline Normalized Shannon Entropy $b$, mean \pm SD $(\times 1000)$ & $8.9 \pm 2.3$ & $9.6 \pm 1.4$ & 0.4 & & \\
\hline Nucleotide Mutation Frequency ${ }^{b}$, mean \pm SD $(\times 1000)$ & $6.2 \pm 3.9$ & $2.9 \pm 3.1$ & 0.03 & 0.98 & $1(0.78-1.3)$ \\
\hline
\end{tabular}

Statistically significant $p$ values are in bold. OR: Odds Ratio; 95\% CI: 95\% confidence interval. ${ }^{\text {a }}$ IFNL4 (rs368234815) was not included in the analysis due to its high linkage disequilibrium with IFNL3 (rs12979860) SNP in the analyzed population (Table 1). ${ }^{\mathrm{b}}$ Calculated on 72 samples. 
Table 7. Cont.

C

\begin{tabular}{|c|c|c|c|c|c|}
\hline \multirow{2}{*}{ Patients Characteristics } & \multirow{2}{*}{$\begin{array}{c}\text { RASs } \\
(n=22)\end{array}$} & \multirow{2}{*}{$\begin{array}{l}\text { No RASs } \\
(n=57)\end{array}$} & \multirow{2}{*}{$\begin{array}{c}\text { Univariate Analysis } \\
p \text { Value }\end{array}$} & \multicolumn{2}{|c|}{ Multivariate Analysis } \\
\hline & & & & $p$ Value & OR $(95 \% \mathrm{CI})$ \\
\hline Male gender, no. (\%) & $17(77.2)$ & $36(63.2)$ & 0.29 & & \\
\hline Age (years), mean $\pm \mathrm{SD}$ & $55.1 \pm 4.8$ & $52.5 \pm 6.1$ & 0.59 & & \\
\hline $\mathrm{HCV}$ viral load $\left(\log _{10}\right)$, mean $\pm \mathrm{SD}$ & $6.2 \pm 3.1$ & $5.9 \pm 1.9$ & 0.27 & & \\
\hline HCV subtype $1 b$, no. $(\%)$ & $18(81.8)$ & $32(56.1)$ & 0.04 & 0.57 & $1.51(0.36-6.4)$ \\
\hline METAVIR Score F4, no. (\%) & $8(36.4)$ & $12(21.05)$ & 0.25 & & \\
\hline HIV co-infection, no. $(\%)$ & $2(9.1)$ & $3(5.3)$ & 0.61 & & \\
\hline Previous failure to PegIFN/RBV treatment, no. (\%) & $10(45.4)$ & $16(28.1)$ & 0.18 & & \\
\hline IFNL3 SNP (rs12979860) CC genotype ${ }^{a}$, no. $(\%)$ & $12(54.5)$ & $10(17.5)$ & 0.002 & 0.01 & $6.3(1.5-25.8)$ \\
\hline Normalized Shannon Entropy ${ }^{b}$, mean \pm SD $(\times 1000)$ & $21.2 \pm 1.5$ & $15.8 \pm 2.9$ & 0.33 & & \\
\hline Nucleotide Mutation Frequency ${ }^{b}$, mean \pm SD $(\times 1000)$ & $7.9 \pm 2.6$ & $6.8 \pm 4.1$ & 0.21 & & \\
\hline
\end{tabular}

Statistically significant $p$ values are in bold. OR: Odds Ratio; 95\% CI: 95\% confidence interval. ${ }^{\text {a }}$ IFNL4 (rs368234815) was not included in the analysis due to its high linkage disequilibrium with IFNL3 (rs12979860) SNP in the analyzed population (Table 1). ${ }^{\mathrm{b}}$ Calculated on 72 samples. 


\subsection{Factors Related to the Presence of Baseline RASs}

In univariate analyses, several factors were significantly associated with the presence of baseline RASs in the NS5A, NS5B and NS3 regions (Table 7).

In a multivariate logistic regression model, HCV subtype 1b, IFNL3 CC genotype and values above the median of Shannon entropy and nucleotide mutation frequency were identified as independent predictors of the presence of baseline RASs in the NS5A gene. Among these, IFNL3 CC genotype was the factor with the highest predictive value $(p=0.0005)$. In the NS3 gene, this host genetic factor was also identified as the only independent predictor of the presence of RASs at baseline $(p=0.01)$. No factor was independently associated with the presence of RASs in the NS5B genomic region after the multivariate analysis (Table 7).

\subsection{Effect of Baseline RASs on Treatment Outcome}

Sixty of the $86(69.8 \%$ ) recruited patients (28 subtype 1a and 32 subtype 1 b) were treated with DAAs after enrolment in this study. Most of them $(43 / 60 ; 71.7 \%)$ received SOF based combination: SOF + DCV for 12 weeks $(28 / 43,65.1 \%)$, SOF + DCV for 24 weeks $(13 / 43,30.2 \%)$, SOF + SMV for 12 weeks $(1 / 43,2.3 \%)$, and SOF $+\operatorname{LDV}$ for 12 weeks $(1 / 43,2.3 \%)$. One patient received DCV + Peg-IFN/RBV for 24 weeks (1/60, 1.7\%) and the remaining 16 patients were treated for 24 to 48 weeks during 2012 to 2013 with triple therapy including Peg-IFN/RBV in combination with a first-generation NS3 protease inhibitor: Four received BOC + Peg-IFN/RBV (4/60; 6.7\%) and 12 TVR + Peg-IFN/RBV $(12 / 60 ; 20 \%)$.

Overall, 93.3\% (56/60) of the patients achieved SVR. Among them, 27 patients $(27 / 56 ; 48.2 \%)$ exhibited at baseline a RAS (or a combination of RASs) related to the DAA-regimen. Treatment failure was observed in four $(6.7 \%)$ cirrhotic and treatment-experienced patients (one subtype 1a and three subtype $1 \mathrm{~b}$ ) who relapsed after receiving triple therapy. One of the subtype $1 \mathrm{~b}$ patients had a low-level baseline RAS (S122G) to protease inhibitors.

\section{Discussion}

The World Health Organization (WHO) has declared that HCV should be eliminated as a public health threat by 2030 [2]. Although DAAs seem a promising tool for viral elimination, HCV treatment fails in approximately $2.5 \%$ to $5 \%$ of patients and this may often occur in the presence of RASs [1]. Moreover, it has been reported that the frequencies of RASs differ between geno- and subtypes, geographical region and method of sequencing [33]. In addition, several viral, host and treatment factors can influence the emergence of RASs [18]. Therefore, in order to reach the worldwide elimination goals, RAS prevalence should be evaluated in individual countries or regions.

In this study, the combined results from both sequencing methods revealed that the frequency of natural RASs varied according to the analyzed viral region, as RASs were more frequently observed in the NS3 when compared to their frequency in the NS5A (39.2\% vs. $25 \%$, respectively; $p=0.06)$ and in the NS5B genes $(39.2 \%$ vs. $8.9 \% ; p<0.0001)$.

This disparity in the prevalence of RASs between the three genomic regions is a possible reflection of the fact that the substitution rates in the different proteins may be constrained by the function that each one of them fulfills in the biology of the HCV. Since the genetic variability is not evenly distributed across the viral genome [34], different evolutionary processes shape the different genetic barriers for the development of resistance of each DAA family, which are similar between NS5A and NS3 protease, but higher for NS5B polymerase [34].

In the NS3 and NS5A regions, the frequencies of natural RAS were higher than those observed in previous studies [10,35], but similar to those reported in Argentina for NS3 [25] and in Brazil [17,36,37] when taking into consideration the sequencing method and cut-off value used. Notably, when the analysis was limited to amino acid substitutions associated with a clinically relevant level of resistance (defined as "likely resistant"), their prevalence was lower in both genomic regions when compared 
to other studies $[10,22,35,38]$. In this regard, in the NS5A protein, combining the results from both sequencing methods, mutations M28V and L31M were only detected in two subtype 1a and two subtype $1 \mathrm{~b}$-infected patients, respectively. Moreover, RAS Y93H, which confers high-level resistance to DCV, OMV, LDV and ELB [39], was observed in one subtype 1a-infected patient at a low frequency $(3 \%)$ only after performing NGS. In the NS3 region, the clinically important RAS Q80K was only detected in one patient belonging to subtype 1a clade 1 . This finding is in agreement with amino acid signature analyses from United States and Europe sequences in which Q80K polymorphism was only found in subtype 1a clade 1 and not clade $2[40,41]$.

The low prevalence of the clinically relevant RASs in the NS3 and NS5A regions in this study contrasts with results from Asia, Europe and USA [35,38,42-44], but it is similar to Argentinean and Brazilian reports $[17,25,36,37]$. The reasons for this discrepancy remain unclear as there is still little information about the genetic variability of the viral genes of HCV isolates from Latin America. However, this finding could be associated to geographical factors, as previously suggested $[45,46]$.

In the NS5B region, the prevalence of RASs was lower than those reported by other studies [35,47]. None of the patients carried the S282T mutation, which is the signature substitution associated with resistance to $\mathrm{SOF}$ in vitro for all $\mathrm{HCV}$ genotypes [38]. This finding is in agreement with previous studies which reported that $\mathrm{S} 282 \mathrm{~T}$ is rarely $(<1 \%)$ selected in patients treated with a SOF-based regimen and is not detected in treatment-naïve genotype 1 patients [42].

In this study, natural substitutions were detected at baseline in both subtypes, with a higher prevalence of RASs among subtype $1 \mathrm{~b}$ samples in all three HCV genomic regions. This finding is in agreement with studies carried out in Italy [42], Argentina [25] and Brazil [17,35,45,48]; whereas a higher prevalence of RASs in subtype 1a sequences was observed in Europe and USA [10,22,49,50] and in two reports from Uruguay in which the number of analyzed subtype $1 \mathrm{~b}$ sequences was relatively low [51,52].

The higher presence of Q80K among subtype 1a samples reported in Europe and USA, as well as the low prevalence of this subtype and this mutation among the samples of this study $[4,25]$ could be possibly related to the different prevalence of RASs in each region. These geographic discrepancies highlight the genetic diversity present in both the natural RASs found in Latin American countries and the evolutionary relationships between Argentinean and other worldwide isolates, probably linked to the Italian immigration occurred in the 19th century.

Regarding the differences observed between subtypes, the nucleotide mutation frequencies in the NS3 and NS5A regions revealed that the genetic diversity was significantly higher among subtype $1 \mathrm{~b}$-infected patients compared to those infected with subtype $1 \mathrm{a}$. Subtype $1 \mathrm{~b}$ patients were, on average, older than those infected with subtype 1a (Table 1) and may have been infected-and possibly transmitting HCV-for longer periods of time [53], leading to a higher diversity in the viral genome. Finally, the higher prevalence of multiple RASs in subtype $1 \mathrm{~b}$ genomes could enhance their replication capacity, as was previously reported [54,55]. Taking this into account, HCV subtype $1 \mathrm{~b}$ infection may have a more unfavorable treatment outcome in Argentina than the expected in other geographical regions, particularly with some DAA regimens. However, the baseline presence of RASs in both HCV subtypes did not appear to affect therapy outcome on a limited sample of patients treated with DAAs in this study.

The need to routinely test for RASs at baseline has been recommended for Q80K in subtype 1a prior to using SMV in interferon-containing regimens, and in patients with cirrhosis that are going to be treated with SOF and SMV. For NS5A inhibitors, it is recommended to test for RASs in subtype 1a patients when using GZR + EBR [12]. The results presented herein suggest that routine testing for RASs at baseline would not be necessary for subtype 1a patients in this population, as their frequencies are low. However, the development of a resistance monitoring system is required as this scenario may change in the near future.

It has been reported that not only the presence of a particular RAS but also the RAS dominancy $(>15 \%$ to $25 \%)$ in the patient's quasispecies has an impact on treatment outcome [56,57], although a 
recent study suggests that minority RASs present at much lower than $15 \%$ may also be relevant for treatment planning [58]. In this regard, this is the first report in Argentina that screened HCV drug resistance using NGS. This technology revealed RASs—not detected by automated sequencing-in $10.5 \%$ and $11.1 \%$ of the NS5A and NS3 samples. Among them, only two RASs were detected at a frequency above $15 \%$ among the patient's viral quasispecies: M28V (with a frequency of $21 \%$ ) in NS5A and Q80L (with a frequency of 21\%) in NS3. This finding supports the fact that deep sequencing has not been proven clinically relevant for RASs testing [59]. Indeed, NGS methodology is costly, too laborious, and technically challenging for many laboratories [60] and, thus, NGS could not yet be ready for routine clinical practice in Argentina.

Although Sanger automated sequencing is generally limited to the detection of variants with greater than $20 \%$ of prevalence [16], the two RASs mentioned above could not be detected by automated sequencing. This lack of correlation between both sequencing methods was probably due to the fact that both samples exhibited low viral loads ( $3.2 \log _{10}$ copies $/ \mathrm{mL}$ ), as it was previously reported [61]. In fact, it has been estimated that the efficiency of RNA extraction and cDNA synthesis is $1 \%$ to $10 \%$ [62]; thus, in low viral load samples, the small number of molecules present in the cDNA could be better examined by the higher analytical sensitivity of NGS [63].

Regarding host factors, it has been reported that the IFNL4 TT genotype, which has a more efficient antiviral response to HCV infection, is strongly associated with RAS Y93H in the subtype $1 \mathrm{~b}$ NS5A protein, resulting in selection for viral adaptations $[19,21]$. In this study, univariate and multivariate analyses revealed that the IFNL3 CC genotype was identified as an independent predictor of the presence of RASs at baseline in NS5A and NS3 genomic regions. Therefore, differences in the frequency of NS5A and NS3 RASs could reflect disparities in the selection pressure against HCV due to genetic variations within the IFNL3/4 locus.

Finally, this study has certain limitations that need to be considered. First, NS3, NS5A and NS5B genes could not be amplified in some patients due to the low volume of stored serum and/or RNA samples. Second, the number of analyzed sequences was not so large. However, other studies included a similar—or even smaller—number of patients [46,51,52]. Finally, this study recruited only genotype 1 patients from Buenos Aires and the metropolitan region, and thus excluded patients infected with other genotypes or from distant areas of Buenos Aires, where the ancestry composition of the population and the prevalence of host genetic factors differ [64]. Therefore, these findings should not be generalized or transferable to the whole country.

\section{Conclusions}

Decisions regarding which combinations of DAAs to use remain challenging [65,66]. This study depicts a current scenario on DAA resistance in Buenos Aires, Argentina. In summary, the frequencies of natural NS5A and NS3 substitutions were similar than those previously reported in this geographic region. In the NS5B region, the prevalence of RASs was lower than those previously reported. Notably, the prevalence of clinically relevant RASs in the three analyzed genes was lower than those observed around the world. Although tested on a limited sample of patients in this study, the baseline presence of RASs in both HCV subtypes did not appear to affect therapy outcome. Despite the fact that NGS allowed a more complete analysis of RASs, its usefulness may be limited in this population. These results support the need to define the resistance testing in each country since the RASs have very different worldwide prevalence.

Supplementary Materials: The following are available online at http:/ /www.mdpi.com/1999-4915/11/1/3/s1, Figure S1: Maximum-likelihood phylogenetic tree (GTR+ $+\mathrm{I}$ model for nucleotide substitutions) including 48 references sequences (in black) and the $84 \mathrm{HCV}-\mathrm{NS} 5 \mathrm{~A}$ samples of this study (in red). The numbers at each node correspond to bootstrap values obtained with 100 replicates (values lower than 70 are not shown); Figure S2: Maximum-likelihood phylogenetic tree (GTR $+\Gamma+\mathrm{I}$ model for nucleotide substitutions) including 48 references sequences (in black) and the $79 \mathrm{HCV}-\mathrm{NS} 5 \mathrm{~B}$ samples of this study (in red). The numbers at each node correspond to bootstrap values obtained with 100 replicates (values lower than 70 are not shown); Figure S3: Maximum-likelihood phylogenetic tree (GTR $+\Gamma+\mathrm{I}$ model for nucleotide substitutions) including 48 references 
sequences (in black) and the $79 \mathrm{HCV}-\mathrm{NS} 3$ samples of this study (in red). The numbers at each node correspond to bootstrap values obtained with 100 replicates (values lower than 70 are not shown).

Author Contributions: I.E. performed the experiments, analyzed the data, and wrote the paper. S.M. recruited the patients, contributed to patients' data and wrote the paper. L.H., O.G. and A.G. recruited the patients and contributed to patients' data. A.F. performed the experiments. D.F. conceived and designed the experiments and wrote the paper. J.T. conceived and designed the experiments, analyzed the data and wrote the paper.

Funding: This study was partly supported by grants from the Research Council of the Italian Hospital of Buenos Aires, Instituto Universitario del Hospital Italiano de Buenos Aires, and Agencia Nacional de Investigaciones Científica y Técnicas, Hospital Italiano de Buenos Aires PICTO 2016-0015.

Acknowledgments: The authors would like to thank the patients for their cooperation, Tech. Noelia Bravo for technical assistance and Ariel Cessario, B.Eng. for entropy data analysis. The use of the Bioruptor ${ }^{\circledR S o n i c a t i o n}$ System was kindly allowed by the Instituto de Investigaciones Farmacológicas, Universidad de Buenos Aires, Consejo Nacional de Investigaciones Científicas y Técnicas.

Conflicts of Interest: Dr. Gadano has been a speaker of Bristol Myer Squibb, Gador, Gilead, Novartis and Abbvie. He also received educational grants from Gilead, Bristol Myers Squibb and Gador and research grants from Gilead and Bristol Myers Squibb. Dr. Marciano has been a speaker of Bristol Myer Squibb, Gador, Gilead and Abbvie. Additionally, he received educational grants from Gilead, Bristol Myers Squibb and Gador and research grants from Gilead and Bristol Myers Squibb. Dr. Haddad received educational grants from Gilead, Bristol Myer Squibb and Abbvie. The remaining authors declare no conflict of interest. The funders had no role in the design of the study; in the collection, analyses, or interpretation of data; in the writing of the manuscript, or in the decision to publish the results.

\section{References}

1. Polaris Observatory HCV Collaborators. Global prevalence and genotype distribution of hepatitis $C$ virus infection in 2015: A modelling study. Lancet Gastroenterol. Hepatol. 2017, 2, 161-176. [CrossRef]

2. World Health Organization. Global Hepatitis Report 2017. Available online: http://who.int/hepatitis/ publications / global-hepatitis-report2017/en/ (accessed on 26 October 2018).

3. Gaite, L.A.; Marciano, S.; Galdame, O.A.; Gadano, A.C. Hepatitis C in Argentina: Epidemiology and treatment. Hepatic Med. 2014, 6, 35-43. [CrossRef]

4. Golemba, M.D.; Di Lello, F.A.; Bessone, F.; Fay, F.; Benetti, S.; Jones, L.R.; Campos, R.H. High prevalence of hepatitis $C$ virus genotype $1 \mathrm{~b}$ infection in small town of Argentina. Phylogenetic and Bayesian coalescent analysis. PLoS ONE 2010, 5, e8751. [CrossRef] [PubMed]

5. Asselah, T.; Boyer, N.; Saadoun, D.; Martinot-Peignoux, M.; Marcellin, P. Direct-acting antivirals for the treatment of hepatitis $C$ virus infection: Optimizing current IFN-free treatment and future perspectives. Liver Int. 2016, 36, 47-57. [CrossRef] [PubMed]

6. Pawlotsky, J.M. Hepatitis C Virus Resistance to Direct-Acting Antiviral Drugs in Interferon-Free Regimens. Gastroenterology 2016, 151, 70-86. [CrossRef] [PubMed]

7. Lontok, E.; Harrington, P.; Howe, A.; Kieffer, T.; Lennerstrand, J.; Lenz, O.; McPhee, F.; Mo, H.; Parkin, N.; Pilot-Matias, T.; et al. Hepatitis C virus drug resistance-associated substitutions: State of the art summary. Hepatology 2015, 62, 1623-1632. [CrossRef]

8. Bagaglio, S.; Uberti-Foppa, C.; Morsica, G. Resistance Mechanisms in Hepatitis C Virus: Implications for Direct-Acting Antiviral Use. Drugs 2017, 77, 1043-1055. [CrossRef]

9. Asociación Argentina para el Estudio de las Enfermedades del Hígado (AAEEH). Recomendaciones para el Tratamiento de la Hepatitis Crónica por virus C. Indicaciones de Tratamiento 2018. Available online: http:/ / aaeeh.org.ar/guias-y-consensos / guias / (accessed on 26 October 2018).

10. Sarrazin, C.; Dvory-Sobol, H.; Svarovskaia, E.S.; Doehle, B.P.; Pang, P.S.; Chuang, S.M.; Ma, J.; Ding, X.; Afdhal, N.H.; Kowdley, K.V.; et al. Prevalence of Resistance-Associated Substitutions in HCV NS5A, NS5B, or NS3 and Outcomes of Treatment With Ledipasvir and Sofosbuvir. Gastroenterology 2016, 151, 501-512. [CrossRef]

11. EASL. Recommendations on Treatment of Hepatitis C 2016, Update of September 2016. Available online: http:/ / www.easl.eu/medias/cpg/HCV2016/English-report.pdf (accessed on 11 December 2018).

12. AASLD-IDSA HCV Guidance Panel. Hepatitis C Guidance 2018 Update: AASLD-IDSA Recommendations for Testing, Managing, and Treating Hepatitis C Virus Infection. Clin. Infect. Dis. 2018, 67, 1477-1492. [CrossRef] 
13. Perales, C. Quasispecies dynamics and clinical significance of HCV antiviral resistance. Int. J. Antimicrob. Agents 2018. [CrossRef]

14. Feld, J.J. Resistance testing: Interpretation and incorporation into HCV treatment algorithms. Clin. Liver Dis. 2017, 9, 115-120, doiorg/101002/cld631. [CrossRef]

15. Sorbo, M.C.; Cento, V.; Di Maio, V.C.; Howe, A.Y.M.; Garcia, F.; Perno, C.F.; Ceccherini-Silberstein, F. Hepatitis $\mathrm{C}$ virus drug resistance associated substitutions and their clinical relevance: Update 2018. Drug Resist. Update 2018, 37, 17-39. [CrossRef] [PubMed]

16. Fourati, S.; Pawlotsky, J.M. Virologic Tools for HCV Drug Resistance Testing. Viruses 2015, 7, 6346-6359. [CrossRef] [PubMed]

17. Gaspareto, K.V.; Ribeiro, R.M.; de Mello Malta, F.; Gomes-Gouvêa, M.S.; Muto, N.H.; Romano, C.M.; Mendes-Correa, M.C.; Carrilho, F.J.; Sabino, E.C.; Rebello Pinho, J.R. Resistance-associated variants in HCV subtypes $1 \mathrm{a}$ and $1 \mathrm{~b}$ detected by Ion Torrent sequencing platform. Antivir. Ther. 2016, 21, 653-660. [CrossRef] [PubMed]

18. Cavalcante, L.N.; Lyra, A.C. Predictive factors associated with hepatitis C antiviral therapy response. World J. Hepatol. 2015, 7, 1617-1631. [CrossRef] [PubMed]

19. Akamatsu, S.; Hayes, C.N.; Ochi, H.; Uchida, T.; Kan, H.; Murakami, E.; Abe, H.; Tsuge, M.; Miki, D.; Akiyama, R.; et al. Association between variants in the interferon lambda 4 locus and substitutions in the hepatitis C virus non-structural protein 5A. J. Hepatol. 2015, 63, 554-563. [CrossRef] [PubMed]

20. Itakura, J.; Kurosaki, M.; Takada, H.; Nakakuki, N.; Matsuda, S.; Gondou, K.; Asano, Y.; Hattori, N.; Itakura, Y.; Tamaki, N.; et al. Naturally occurring, resistance-associated hepatitis C virus NS5A variants are linked to interleukin-28B genotype and are sensitive to interferon-based therapy. Hepatol. Res. 2015, 45, E115-E121. [CrossRef]

21. Peiffer, K.H.; Sommer, L.; Susser, S.; Vermehren, J.; Herrmann, E.; Döring, M.; Dietz, J.; Perner, D.; Berkowski, C.; Zeuzem, S.; et al. Interferon lambda 4 genotypes and resistance-associated variants in patients infected with hepatitis $C$ virus genotypes 1 and 3. Hepatology 2016, 63, 63-73. [CrossRef]

22. Chen, Z.W.; Li, H.; Ren, H.; Hu, P. Global prevalence of pre-existing HCV variants resistant to direct-acting antiviral agents (DAAs): Mining the GenBank HCV genome data. Sci. Rep. 2016, 6, 20310. [CrossRef]

23. Plaza, Z.; Soriano, V.; Vispo, E.; del Mar Gonzalez, M.; Barreiro, P.; Seclén, E.; Poveda, E. Prevalence of natural polymorphisms at the HCV NS5A gene associated with resistance to daclatasvir, an NS5A inhibitor. Antivir. Ther. 2012, 17, 921-926. [CrossRef]

24. Treviño, A.; de Mendoza, C.; Parra, P.; Rodríguez, C.; Madejón, A.; Plaza, Z.; del Romero, J.; Poveda, E.; Soriano, V. Natural polymorphisms associated with resistance to new antivirals against HCV in newly diagnosed HIV-HCV-coinfected patients. Antivir. Ther. 2011, 16, 413-416. [CrossRef] [PubMed]

25. Martínez, A.P.; Culasso, A.C.A.; Pérez, P.S.; Romano, V.; Campos, R.H.; Ridruejo, E.; García, G.; Di Lello, F.A. Polymorphisms associated with resistance to protease inhibitors in naïve patients infected with hepatitis $C$ virus genotype 1 in Argentina: Low prevalence of Q80K. Virus Res. 2017, 240, 140-146. [CrossRef] [PubMed]

26. Hall, T.A. BioEdit: A user-friendly biological sequence alignment editor and analysis program for Windows 95/98/NT. Nucleic Acids Symp. Ser. 1999, 41, 95-98.

27. Tamura, K.; Stecher, G.; Peterson, D.; Filipski, A.; Kumar, S. MEGA6: Molecular Evolutionary Genetics Analysis Version 6.0. Mol. Biol. Evol. 2013, 30, 2725-2729. [CrossRef] [PubMed]

28. Page, R.D. Visualizing phylogenetic trees using TreeView. Curr. Protoc. Bioinform. 2002. [CrossRef] [PubMed]

29. Beerenwinkel, N.; Günthard, H.F.; Roth, V.; Metzner, K.J. Challenges and opportunities in estimating viral genetic diversity from next-generation sequencing data. Front. Microbiol. 2012, 3, 329. [CrossRef]

30. Vandenbroucke, I.; Van Marck, H.; Mostmans, W.; Van Eygen, V.; Rondelez, E.; Thys, K.; Van Baelen, K.; Fransen, K.; Vaira, D.; Kabeya, K.; et al. HIV-1 V3 envelope deep sequencing for clinical plasma specimens failing in phenotypic tropism assays. AIDS Res. Ther. 2010, 7, 4. [CrossRef] [PubMed]

31. Zagordi, O.; Bhattacharya, A.; Eriksson, N.; Beerenwinkel, N. ShoRAH: Estimating the genetic diversity of a mixed sample from next-generation sequencing data. BMC Bioinform. 2011, 12, 119. [CrossRef] [PubMed]

32. Cabot, B.; Martell, M.; Esteban, J.I.; Sauleda, S.; Otero, T.; Esteban, R.; Guàrdia, J.; Gómez, J. Nucleotide and Amino Acid Complexity of Hepatitis C Virus Quasispecies in Serum and Liver. J. Virol. 2000, 74, 805-811. [CrossRef] 
33. Dietz, J.; Susser, S.; Berkowski, C.; Perner, D.; Zeuzem, S.; Sarrazin, C. Consideration of viral resistance for optimization of direct antiviral therapy of hepatitis C virus genotype 1-infected patients. PLoS ONE 2015, 10, e0134395. [CrossRef]

34. Simmonds, P. Genetic diversity and evolution of hepatitis C virus-15 years on. J. Gen. Virol. 2004, 85, 3173-3188. [CrossRef] [PubMed]

35. Bertoli, A.; Sorbo, M.C.; Aragri, M.; Lenci, I.; Teti, E.; Polilli, E.; Di Maio, V.C.; Gianserra, L.; Biliotti, E.; Masetti, C.; et al. Prevalence of Single and Multiple Natural NS3, NS5A and NS5B Resistance-Associated Substitutions in Hepatitis C Virus Genotypes 1-4 in Italy. Sci. Rep. 2018, 8, 8988. [CrossRef] [PubMed]

36. De Carvalho, I.M.; Alves, R.; de Souza, P.A.; da Silva, E.F.; Mazo, D.; Carrilho, F.J.; Queiroz, A.T.; Pessoa, M.G. Protease inhibitor resistance mutations in untreated Brazilian patients infected with HCV: Novel insights about targeted genotyping approaches. J. Med. Virol. 2014, 86, 1714-1721. [CrossRef] [PubMed]

37. Peres-da-Silva, A.; Almeida, A.J.; Lampe, E. Genetic diversity of NS3 protease from Brazilian HCV isolates and possible implications for therapy with direct-acting antiviral drugs. Mem. Inst. Oswaldo Cruz 2012, 107, 254-261. [CrossRef] [PubMed]

38. Wei, L.; Omata, M.; Lim, Y.S.; Xie, Q.; Hou, J.L.; Jia, J.; Hedskog, C.; Martin, R.; Doehle, B.; Yang, J.; et al. HCV phylogenetic signature and prevalence of pretreatment NS5A and NS5B NI-Resistance associated substitutions in HCV-Infected patients in Mainland China. Antivir. Res. 2018, 158, 178-184. [CrossRef] [PubMed]

39. Krishnan, P.; Schnell, G.; Tripathi, R.; Beyer, J.; Reisch, T.; Zhang, X.; Setze, C.; Rodrigues, L., Jr.; Burroughs, M.; Redman, R.; et al. Analysis of hepatitis $\mathrm{C}$ virus genotype $1 \mathrm{~b}$ resistance variants in Japanese patients treated with Paritaprevir-Ritonavir and Ombitasvir. Antimicrob. Agents Chemother. 2016, 60, 1106-1113. [CrossRef] [PubMed]

40. De Luca, A.; Di Giambenedetto, S.; Lo Presti, A.; Sierra, S.; Prosperi, M.; Cella, E.; Giovanetti, M.; Torti, C.; Caudai, C.; Vicenti, I.; et al. Two distinct hepatitis C virus genotype 1a clades have different geographical distribution and association with natural resistance to NS3 protease inhibitors. Open Forum Infect. Dis. 2015, 2, ofv043. [CrossRef] [PubMed]

41. McCloskey, R.M.; Liang, R.H.; Joy, J.B.; Krajden, M.; Montaner, J.S.; Harrigan, P.R.; Poon, A.F. Global origin and transmission of hepatitis C virus nonstructural protein 3 Q80K polymorphism. J. Infect. Dis. 2015, 211, 1288-1295; [CrossRef]

42. Paolucci, S.; Fiorina, L.; Mariani, B.; Gulminetti, R.; Novati, S.; Barbarini, G.; Bruno, R.; Baldanti, F. Naturally occurring resistance mutations to inhibitors of HCV NS5A region and NS5B polymerase in DAA treatment-naïve patients. Virol. J. 2013, 10, 355. [CrossRef]

43. Morel, V.; Duverlie, G.; Brochot, E. Patients eligible for treatment with simeprevir in a French center. J. Clin. Virol. 2014, 61, 149-151. [CrossRef]

44. Sarrazin, C.; Lathouwers, E.; Peeters, M.; Daems, B.; Buelens, A.; Witek, J.; Wyckmans, Y.; Fevery, B.; Verbinnen, T.; Ghys, A.; et al. Prevalence of the hepatitis C virus NS3 polymorphism Q80K in genotype 1 patients in the European region. Antivir. Res. 2015, 116, 10-16. [CrossRef] [PubMed]

45. Peres-da-Silva, A.; Almeida, A.J.; Lampe, E. Mutations in hepatitis C virus NS3 protease domain associated with resistance to specific protease inhibitors in antiviral therapy naïve patients. Arch. Virol. 2010, 155, 807-811. [CrossRef] [PubMed]

46. Hoffmann, L.; Ramos, J.A.; Souza, E.V.; Araújo Ramos, A.L.; Villela-Nogueira, C.A.; Urményi, T.P.; Tanuri, A.; Rondinelli, E.; Silva, R. Dynamics of resistance mutations to NS3 protease inhibitors in a cohort of Brazilian patients chronically infected with hepatitis $C$ virus (genotype 1) treated with pegylated interferon and ribavirin: A prospective longitudinal study. Virol. J. 2013, 10, 57. [CrossRef] [PubMed]

47. Noble, C.F.; Malta, F.; Lisboa-Neto, G.; Gomes-Gouvêa, M.S.; Leite, A.G.B.; de Castro, V.F.D.; Santana, R.A.F.; Carrilho, F.J.; Mendes-Correa, M.C.; Pinho, J.R.R. Natural occurrence of NS5B inhibitor resistance-associated variants in Brazilian patients infected with HCV or HCV and HIV. Arch. Virol. 2017, 162, 165-169. [CrossRef] [PubMed]

48. Malta, F.; Gaspareto, K.V.; Lisboa-Neto, G.; Carrilho, F.J.; Mendes-Correa, M.C.; Pinho, J.R.R. Prevalence of naturally occurring NS5A resistance-associated substitutions in patients infected with hepatitis $C$ virus subtype 1a, 1b, and 3a, co-infected or not with HIV in Brazil. BMC Infect. Dis. 2017, 17, 716. [CrossRef] [PubMed] 
49. Margeridon-Thermet, S.; Le Pogam, S.; Li, L.; Liu, T.F.; Shulman, N.; Shafer, R.W.; Najera, I. Similar prevalence of low-abundance drug-resistant variants in treatment-naïve patients with genotype $1 \mathrm{a}$ and $1 \mathrm{~b}$ hepatitis $C$ virus infections as determined by ultradeep pyrosequencing. PLoS ONE 2014, 9, e105569. [CrossRef] [PubMed]

50. Larrat, S.; Vallet, S.; David-Tchouda, S.; Caporossi, A.; Margier, J.; Ramière, C.; Scholtes, C.; Haïm-Boukobza, S.; Roque-Afonso, A.M.; Besse, B.; et al. Naturally Occurring Resistance-Associated Variants of Hepatitis C Virus Protease Inhibitors in Poor Responders to Pegylated Interferon- Ribavirin. J. Clin. Microbiol. 2015, 53, 2195-2202. [CrossRef] [PubMed]

51. Echeverría, N.; Betancour, G.; Gámbaro, F.; Hernández, N.; López, P.; Chiodi, D.; Sánchez, A.; Boschi, S.; Fajardo, A.; Sóñora, M.; et al. Naturally occurring NS3 resistance-associated variants in hepatitis C virus genotype 1: Their relevance for developing countries. Virus Res. 2016, 223, 140-146. [CrossRef] [PubMed]

52. Aldunate, F.; Echeverría, N.; Chiodi, D.; López, P.; Sánchez-Cicerón, A.; Fajardo, A.; Soñora, M.; Cristina, J.; Hernández, N.; Moreno, P. Pretreatment Hepatitis C Virus NS5A/NS5B Resistance-Associated Substitutions in Genotype 1 Uruguayan Infected Patients. Dis. Markers 2018, 5, 1-9. [CrossRef] [PubMed]

53. Culasso, A.C.; Farías, A.; Di Lello, F.A.; Golemba, M.D.; Ré, V.; Barbini, L.; Campos, R. Spreading of hepatitis $\mathrm{C}$ virus subtypes $1 \mathrm{a}$ and $1 \mathrm{~b}$ through the central region of Argentina. Infect. Genet. Evol. 2014, 26, 32-40. [CrossRef] [PubMed]

54. Tong, X.; Li, L.; Haines, K.; Najera, I. Identification of the NS5B S282T resistant variant and two novel amino acid substitutions that affect replication capacity in hepatitis $\mathrm{C}$ virus-infected patients treated with mericitabine and danoprevir. Antimicrob. Agents Chemother. 2014, 58, 3105-3114. [CrossRef] [PubMed]

55. Xu, S.; Doehle, B.; Rajyaguru, S.; Han, B.; Barauskas, O.; Feng, J.; Perry, J.; Dvory-Sobol, H.; Svarovskaia, E.S.; Miller, M.D.; et al. In vitro selection of resistance to sofosbuvir in HCV replicons of genotype-1 to -6 . Antivir. Ther. 2017, 22, 587-597. [CrossRef] [PubMed]

56. Kinugasa, H.; Ikeda, F.; Takaguchi, K.; Mori, C.; Matsubara, T.; Shiraha, H.; Takaki, A.; Iwasaki, Y.; Toyooka, S.; Yamamoto, K. Low frequency of drug-resistant virus did not affect the therapeutic efficacy in daclatasvir plus asunaprevir therapy in patients with chronic HCV genotype-1 infection. Antivir. Ther. 2016, 21, 37-44. [CrossRef] [PubMed]

57. Ikeda, H.; Watanabe, T.; Okuse, C.; Matsumoto, N.; Ishii, T.; Yamada, N.; Shigefuku, R.; Hattori, N.; Matsunaga, K.; Nakano, H.; et al. Impact of resistance associated variant dominancy on treatment in patients with HCV genotype $1 \mathrm{~b}$ receiving daclatasvir/asunaprevir. J. Med. Virol. 2017, 89, 99-105. [CrossRef] [PubMed]

58. Perales, C.; Chen, Q.; Soria, M.E.; Gregori, J.; Garcia-Cehic, D.; Nieto-Aponte, L.; Castells, L.; Imaz, A.; Llorens-Revull, M.; Domingo, E.; et al. Baseline hepatitis C virus resistance-associated substitutions present at frequencies lower than 15\% may be clinically significant. Infect. Drug Resist. 2018, 11, 2207-2210. [CrossRef] [PubMed]

59. Pérez, A.B.; Chueca, N.; García, F. Resistance testing for the treatment of chronic hepatitis $C$ with direct acting antivirals: When and for how long? Germs 2017, 7, 40-44. [CrossRef] [PubMed]

60. Trémeaux, P.; Caporossi, A.; Thélu, M.A.; Blum, M.; Leroy, V.; Morand, P.; Larrat, S. Hepatitis C virus whole genome sequencing: Current methods/issues and future challenges. Crit. Rev. Clin. Lab. Sci. 2016, 53, 341-351. [CrossRef]

61. Arias, A.; López, P.; Sánchez, R.; Yamamura, Y.; Rivera-Amill, V. Sanger and Next Generation Sequencing Approaches to Evaluate HIV-1 Virus in Blood Compartments. Int. J. Environ. Res. Public Health 2018, 15, 1697. [CrossRef]

62. Shafer, R.W.; Levee, D.J.; Winters, M.A.; Richmond, K.L.; Huang, D.; Merigan, T.C. Comparison of QIAamp HCV kit spin columns, silica beads, and phenol-chloroform for recovering human immunodeficiency virus type 1 RNA from plasma. J. Clin. Microbiol. 1997, 35, 520-522.

63. American Society for Microbiology. Report on an American Academy of Microbiology Colloquium Held in Washington, DC in April 2015, 2016. Available online: https://www.asm.org/index.php/ colloquium-reports/item/4462-applications-of-clinical-microbial-next-generation-sequencing (accessed on 11 December 2018).

64. Trinks, J.; Caputo, M.; Hulaniuk, M.L.; Corach, D.; Flichman, D. Hepatitis C virus pharmacogenomics in Latin American populations: Implications in the era of direct-acting antivirals. Pharmgenomics Pers. Med. 2017, 10, 79-91. [CrossRef] 
65. Esposito, I.; Labarga, P.; Barreiro, P.; Fernandez-Montero, J.V.; de Mendoza, C.; Benítez-Gutiérrez, L.; Peña, J.M.; Soriano, V. Dual antiviral therapy for HIV and hepatitis C-Drug interactions and side effects. Expert Opin. Drug Saf. 2015, 14, 421-1434. [CrossRef] [PubMed]

66. Soriano, V.; Labarga, P.; de Mendoza, C.; Fernández-Montero, J.V.; Esposito, I.; Benítez-Gutiérrez, L.; Peña, J.M.; Barreiro, P. New hepatitis C therapies for special patient populations. Expert Opin. Pharmacother. 2016, 17, 217-229. [CrossRef] [PubMed] 